DOI: https://doi.org/10.24127/ajpm.v10i3.3870

\title{
PENGEMBANGAN ANGKET SELF-REGULATION MAHASISWA PENDIDIKAN MATEMATIKA DI MASA PANDEMI COVID-19
}

\author{
Hesty Marwani Siregar ${ }^{1^{*}}$ \\ 1* Universitas Riau, Pekanbaru, Indonesia \\ *Corresponding author. Kampus Bina Widya KM 12,5, 28293, Pekanbaru, Indonesia. \\ E-mail: $\quad \underline{\text { hesty.marwani@lecturer.unri.ac.id }}^{\left.{ }^{*}\right)}$
}

Received 27 September 2020; Received in revised form 13 September 2021; Accepted 28 September 2021

\begin{abstract}
Abstrak
Penelitian ini bertujuan untuk memperoleh instrumen angket self-regulation mahasiswa Pendidikan Matematika pada saat belajar daring di Masa Pandemi Covid-19 yang valid dan reliabel. Penelitian yang dilakukan merupakan design research dengan model pengembangan ADDIE. Data yang diperoleh pada penelitian ini merupakan data kualitatif berupa komentar atau saran perbaikan dari validator terhadap angket self-regulation yang dikembangkan, dan data kuantitatif berupa skor lembar validasi dari validator dan skor yang diperoleh mahasiswa pada saat uji coba instrumen angket self-regulation untuk dihitung validitas dan reliabilitasnya. Teknik analisis data yang digunakan yaitu teknik analisis deskriptif kualitatif dan deskriptif kuantitatif. Penelitian ini memperoleh hasil berupa angket self-regulation mahasiswa pendidikan matematika di masa pandemi Covid-19. Angket yang dihasilkan terdiri dari 15 butir pernyataan yang diturunkan dari 11 indikator, yaitu indikator menetukan tingkat minimal pencapaian, menetapkan tujuan, pemilihan tempat, pemilihan kondisi, persiapan sebelum mengikuti perkuliahan, cara belajar selama mengikuti perkuliahan, cara belajar untuk memperkuat pemahaman, cara menyelesaikan tugas yang diberikan, alokasi waktu, usaha menemukan cara yang tepat untuk memahami pelajaran yang belum dimengerti, dan refleksi diri.
\end{abstract}

Kata kunci: Angket; pandemi Covid-19; pengembangan; self-regulation.

\begin{abstract}
This study aims to obtain a valid and reliable self-regulation questionnaire instrument for Mathematics Education students while studying online during the Covid-19 Pandemic. This research is design research with the ADDIE development model. The data obtained in this study are qualitative data in the form of comments or suggestions for improvement from the validator on the developed self-regulation questionnaire, and quantitative data in the form of validation sheet scores from the validator and scores obtained by students when testing the self-regulation questionnaire instrument to calculate validity and its reliability. The data analysis technique used is descriptive qualitative and descriptive quantitative. This study obtained results in the form of a self-regulation questionnaire for mathematics education students during the Covid-19 pandemic. The resulting questionnaire consists of 15 statement items derived from 11 indicators, namely indicators determining the minimum level of achievement, setting goals, choosing a place, choosing conditions, preparing before attending lectures, learning during lectures, learning to strengthen understanding, how to complete assignments given, time allocation, trying to find the right way to understand the lesson that has not been understood, and self-reflection.
\end{abstract}

Keywords: Covid-19 pandemic; development; self-regulation; questionnaire.

This is an open access article under the Creative Commons Attribution 4.0 International License

\section{PENDAHULUAN}

Adanya lockdown dan physical distancing karena pandemi Covid-19 menyebabkan penutupan sekolah, lembaga pelatihan, dan pendidikan tinggi di sebagian besar Negara di 
dunia, termasuk di Indonesia. Perubahan paradigma dalam pembelajaran, yang biasanya menyampaikan suatu materi dilakukan secara tatap muka menjadi secara online menggunakan berbagai platform atau media teknologi (Rapanta, Botturi, Goodyear, Guàrdia, \& Koole, 2020). Hal inilah yang saat ini harus diadaptasi oleh guru, siswa, dosen, mahasiswa dan lembaga pendidikan. Supaya pembelajaran online berlangsung efektif, materi pembelajaran harus dirancang dengan baik, sehingga pembelajaran tersebut dapat melibatkan mahasiswa dan memfasilitasi pembelajaran yang mandiri.

Pada pembelajaran online, ada hubungan erat antara kemandirian, kematangan, motivasi, dan kedisiplinan (Goulão \& Menedez, 2015). Artinya, semakin besar kemandirian, semakin besar pula kematangan, motivasi, dan kedisiplinan. Hal ini dikarenakan pada pembelajaran online, mahasiswa lebih fleksibel dalam mengikuti pembelajaran. Fleksibilitas ini harus diikuti dengan tanggung jawab yang besar atas proses belajar mereka masing-masing. Oleh karena itu, kemampuan selfregulation sangat diperlukan agar mahasiswa tidak menunda dan menyelesaikan pekerjaan yang diberikan dengan penuh tanggung jawab (Goulão \& Menedez, 2015). Selain itu, mahasiswa membutuhkan self-regulation lebih besar agar tujuan pembelajaran dapat tercapai (Bol \& Garner, 2011).

Self-regulation mengacu pada bagaimana mahasiswa menguasai proses belajar, kemampuan mental, dan kinerja (Zimmerman, 2015). Selfregulation menekankan pada kemampuan mahasiswa dalam memana-jemen dan memahami keseluruhan proses yang terjadi dalam lingkungan sosial (Chaves-Barboza, Trujillo-Torres, López-Núñez, \& Sola-Martínez, 2017).
Woolfolk, Winne, \& Perry menyatakan bahwa self-regulation dalam pembelajaran online didasarkan pada keaktifan dan usaha untuk mencari sumber belajar dalam rangka mencapai tujuan pembelajaran (Yen, Tu, SujoMontes, \& Sealander, 2016). Pembelajar yang mandiri mengoptimalkan strategi belajar melalui self-regulation dan penilaian diri yang berkelanjutan terhadap keberhasilan mereka (Cheng, 2011). Oleh karena itu, self-regulation sebagai prediktor kesuksesan penting untuk dikembangkan oleh dosen melalui pengelolaan proses pembelaja-ran yang baik (Macejka, 2014). Self-regulation dalam belajar dilakukan melalui manajemen diri proaktif, pengetahuan, dan pengendalian diri (Goulão \& Menedez, 2015).

Berbagai penelitian telah memperlihatkan pentingnya self-regulation dalam meningkatkan prestasi akademik siswa. Penelitian yang dilakukan oleh Lin et al menemukan bahwa selfregulation dalam blended learning akan meningkatkan partisipasi dalam kegiatan pembelajaran, manajemen diri yang lebih baik, dan prestasi belajar yang lebih baik ((Lin, Lai, Lai, \& Chang, 2016). Mahasiswa yang memiliki self-regulation berpeluang untuk pencapaian akademik yang lebih baik (Bai \& Guo, 2021). Mahasiswa juga lebih mampu memanajemen dirinya sendiri dan tidak mudah menyerah saat menghadapi kesulitan belajar. Selain itu, self-regulation juga mempengaruhi kemandirian dalam melaksanakan tugas yang diberikan, merencanakan, mengelola, dan berkompeten dalam mengatur waktu yang dimiliki (Qadaristin, 2021).

Namun realitanya, self-regulation yang dimiliki mahasiswa ada yang memadai namun ada pula yang belum memadai. Masih banyak mahasiswa 
yang perlu mengembangkan selfregulation dikarenakan self-regulation mereka yang belum memadai (Dema \& Sinwongsuwat, 2020). Di sisi lain, mahasiswa pendidikan matematika di Universitas Riau sudah memiliki selfregulation yang baik dan mampu beradaptasi dengan pembelajaran selama pandemi Covid-19 (Siregar \& Siregar, 2021). Selain itu, terdapat pula mahasiswa yang memiliki pemahaman mengenai self-regulation, tetapi belum dapat menerapkannya dalam proses belajar mereka (Meesong \& Jaroongkhongdach, 2016).

Berdasarkan uraian di atas, memiliki self-regulation yang baik dalam pembelajaran online sangat diperlukan. Untuk mengetahui apakah mahasiswa telah memiliki selfregulation yang baik, diperlukan suatu alat ukur berupa instrumen yang valid dan reliabel. Salah satu instrumen yang dapat mengukur self-regulation mahasiswa adalah dengan angket. Terkait pembelajaran online, maka angket yang digunakan merupakan angket jenis Online Self-Regulated Learning Questionnaire (OSLQ) yang menggunakan format respon Likert dari sangat setuju hingga tidak setuju serta memuat indikator penetapan tujuan, penataan lingkungan, strategi tugas, manajemen waktu, pencarian bantuan, dan evaluasi diri (Barnard-brak, Lan, \& Paton, 2010).

Penelitian ini memiliki kesamaan dengan penelitian yang dilakukan oleh Muhtarom, Juniati, dan Siswono yang memperoleh angket keyakinan terhadap pemecahan masalah dan pembelajaran matematika yang valid dan reliabel (Muhtarom, Juniati, \& Siswono, 2017). Zuliani, Florentinus, dan Ridlo melalui penelitiannya memperoleh instrumen penilaian karakter pada siswa kelas IV Sekolah Dasar yang valid dan reliabel
(Zuliani, Florentinus, \& Ridlo, 2017). Selanjutnya Sa'adah yang mengembangkan angket minat siswa terhadap proses pembelajaran matematika juga memperoleh angket yang valid (Sa'adah, 2020). Pada penelitianpenelitian tersebut, telah diperoleh instrumen yang valid dan reliabel, tetapi belum ada yang mengukur selfregulation mahasiswa pendidikan matematika. Oleh karena itu, perbedaan penelitian ini dengan penelitian sebelumnya yaitu pada aspek afektif yang diukur pada instrument dan subjek.

Oleh karena dibutuhkan instrumen yang valid dan reliabel serta dapat mengukur self-regulation mahasiswa, sehingga dikembangkan instrumen angket self-regulation untuk mahasiswa pendidikan matematika di masa Pandemi Covid-19. Rumusan masalah pada penelitian ini yaitu apakah instrumen angket self-regulation bagi mahasiswa pendidikan matematika di masa Pandemi Covid-19 valid dan reliable?. Sedangkan tujuan peneltian ini yaitu untuk mengembangkan instrumen angket self-regulation yang valid dan reliabel.

\section{METODE PENELITIAN}

Penelitian ini bertujuan untuk memperoleh instrumen angket selfregulation mahasiswa Pendidikan Matematika pada saat belajar daring di Masa Pandemi Covid-19 yang valid dan reliabel. Penelitian yang dilakukan merupakan design research dengan model pengembangan ADDIE (Analysis, Design, Development, Implementation, dan Evaluation). Kegiatan yang dilakukan pada tahap Analysis yaitu melakukan observasi terkait kebutuhan akan instrumen angket self-regulation, kemudian melakukan studi literatur tetang selfregulation dan menentukan aspek self- 
regulation yang akan diukur. Aspek self-regulation yang digunakan pada penelitian ini, yaitu aspek penetapan tujuan, penataan lingkungan, strategi tugas, manajemen waktu, pencarian bantuan, dan evaluasi diri (Barnard-brak et al., 2010). Pilihan respon yang dapat diberikan untuk tiap butir pernyataan yaitu sangat setuju, setuju, tidak setuju, dan sangat tidak setuju. Proses mendesain instrumen angket dengan menyusun kisi-kisi dan butir pernyataan angket dilakukan pada tahap Design.

Pada tahap Development dilakukan validasi dari dua orang ahli agar mendapat masukan untuk pengembangan dan perbaikan sebelum diujicobakan. Skor validasi yang diperoleh dari kedua validator tersebut kemudian dirata-ratakan dan diinterpretasikan mengacu pada kategori validitas pada Tabel 1.

Tabel 1. Kriteria validitas angket selfregulation

\begin{tabular}{cl}
\hline \multicolumn{1}{c}{ Skor } & \multicolumn{1}{c}{ Kategori } \\
\hline $1,00 \leq \bar{x} \leq 1,75$ & Kurang Valid \\
$1,75<\bar{x} \leq 2,50$ & Cukup Valid \\
$2,50<\bar{x} \leq 3,25$ & Valid \\
$3,25<\bar{x} \leq 4,00$ & Sangat Valid \\
\hline
\end{tabular}

(Subekti \& Akhsani, 2020).

Angket yang memperoleh skor pada kategori valid atau sangat valid, dan telah diperbaiki sesuai saran validator, kemudian ditentukan validitasnya dari skor ujicoba mahasiswa. Angket diuji coba kepada 59 orang mahasiswa Pendidikan Matematika Universitas Riau angkatan 2016 pada tahap Implementation. Hasil ujicoba yang dilakukan pada tahap Implementation selanjutnya dianalisis pada tahap Evaluation. Proses analisis ini dilakukan dengan melihat apakah angket yang dihasilkan valid dan reliabel melalui penghitungan koefisien korelasi validitas dan reliabilitas dengan menggunakan SPSS. Setelah diperoleh koefisien korelasi validitas dan reliabilitas, selanjutnya dilakukan uji keberartian koefisien tersebut dengan menghitung nilai $t$ menggunakan rumus berikut.

$$
t_{\text {hitung }}=r_{x y} \sqrt{\frac{N-2}{1-r_{x y}^{2}}}
$$

Dengan mengambil taraf signifikansi 0,05 , kriteria pengujiannya yaitu

1. jika $t_{\text {hitung }} \leq \mathrm{t}_{\text {kritis }}$, maka soal tidak valid / reliabel

2. jika $t_{\text {hitung }}>t_{\text {kritis }}$, maka soal valid / reliabel

Berdasarkan jenis penelitian, maka tahapan penelitian ini antara lain 1) tahap analysis, dengan menetapkan fokus masalah berdasarkan hasil observasi kebutuhan yaitu terkait pengembangan angket self regulation mahasiswa pendidikan matematika pada saat belajar daring di masa pandemi Covid-19, kemudian mempelajari berbagai literatur mengenai selfregulation, 2) tahap design yaitu merancang instrumen angket selfregulation berupa kisi-kisi angket selfregulation dan angket self-regulation, 3) tahap development, yaitu memberikan kisi-kisi angket selfregulation dan angket self-regulation kepada dua orang validator untuk dinilai validasinya, kemudian merevisi angket self-regulation berdasarkan saran validator, 4) tahap implementation yaitu melakukan ujicoba instrumen angket self-regulation kepada 59 orang mahasiswa Pendidikan Matematika Universitas Riau, kemudian menghitung skor validitas dan reliabilitas angket self-regulation yang telah diujicobakan, 5) tahap evaluation yaitu melakukan analisis terhadap skor validitas dan reliabilitas angket self-regulation, kemudian menyusun butir-butir instru- 
men angket self-regulation mahasiswa Pendidikan Matematika pada saat belajar daring di masa pandemi Covid19 yang telah valid dan reliabel.

Instrumen pengumpulan data pada penelitian ini yaitu lembar validasi angket self-regulation mahasiswa pendidikan matematika di masa Pandemi Covid-19 dan angket selfregulation mahasiswa pendidikan matematika di masa Pandemi Covid-19. Sedangkan teknik pengumpulan data penelitian ini melalui kuesioner.

Data yang diperoleh pada penelitian ini merupakan data kualitatif dan kuantitatif. Data kualitatif yang diperoleh yaitu komentar atau saran perbaikan dari validator terhadap angket self-regulation yang dikembangkan. Selanjutnya, data kuantitatif yang diperoleh dari penelitian ini berupa skor lembar validasi dari validator dan skor yang diperoleh mahasiswa pada saat uji coba instrumen angket self-regulation. Teknik analisis data yang digunakan yaitu teknik analisis deskriptif kualitatif dan kuantitatif. Teknik analisis deskriptif kualitatif dilakukan pada data komentar ataupun saran perbaikan validator. Sedangkan teknik analisis deskriptif kuantitatif dilakukan pada data skor validator dan skor angket selfregulation mahasiswa untuk menentukan validitas dan reliabilitas butir pernyataan instrumen angket self-

Tabel 2. Kisi-kisi angket self-regulation

\begin{tabular}{llcc}
\hline \multirow{2}{*}{ Aspek } & \multicolumn{1}{c}{ Indikator } & \multicolumn{2}{c}{ Butir } \\
\cline { 2 - 4 } & \multicolumn{1}{c}{ Positif } & Negatif \\
\hline Penetapan tujuan & $\begin{array}{l}\text { Menetukan tingkat minimal pencapaian } \\
\text { Menetapkan tujuan }\end{array}$ & 1 & 2 \\
Penataan & $\begin{array}{l}\text { Pemilihan tempat } \\
\text { lingkungan }\end{array}$ & Pemilihan kondisi & 3 \\
Strategi tugas & Persiapan sebelum mengikuti perkuliahan & 6,7 & 5 \\
& Cara belajar selama mengikuti perkuliahan & 8,9 & 10 \\
& Cara belajar untuk memperkuat pemahaman & 12 & 11 \\
Manajemen waktu & Cara menyelesaikan tugas yang diberikan & & 13,14 \\
& Alokasi waktu & 17 & 15,16
\end{tabular}


DOI: https://doi.org/10.24127/ajpm.v10i3.3870

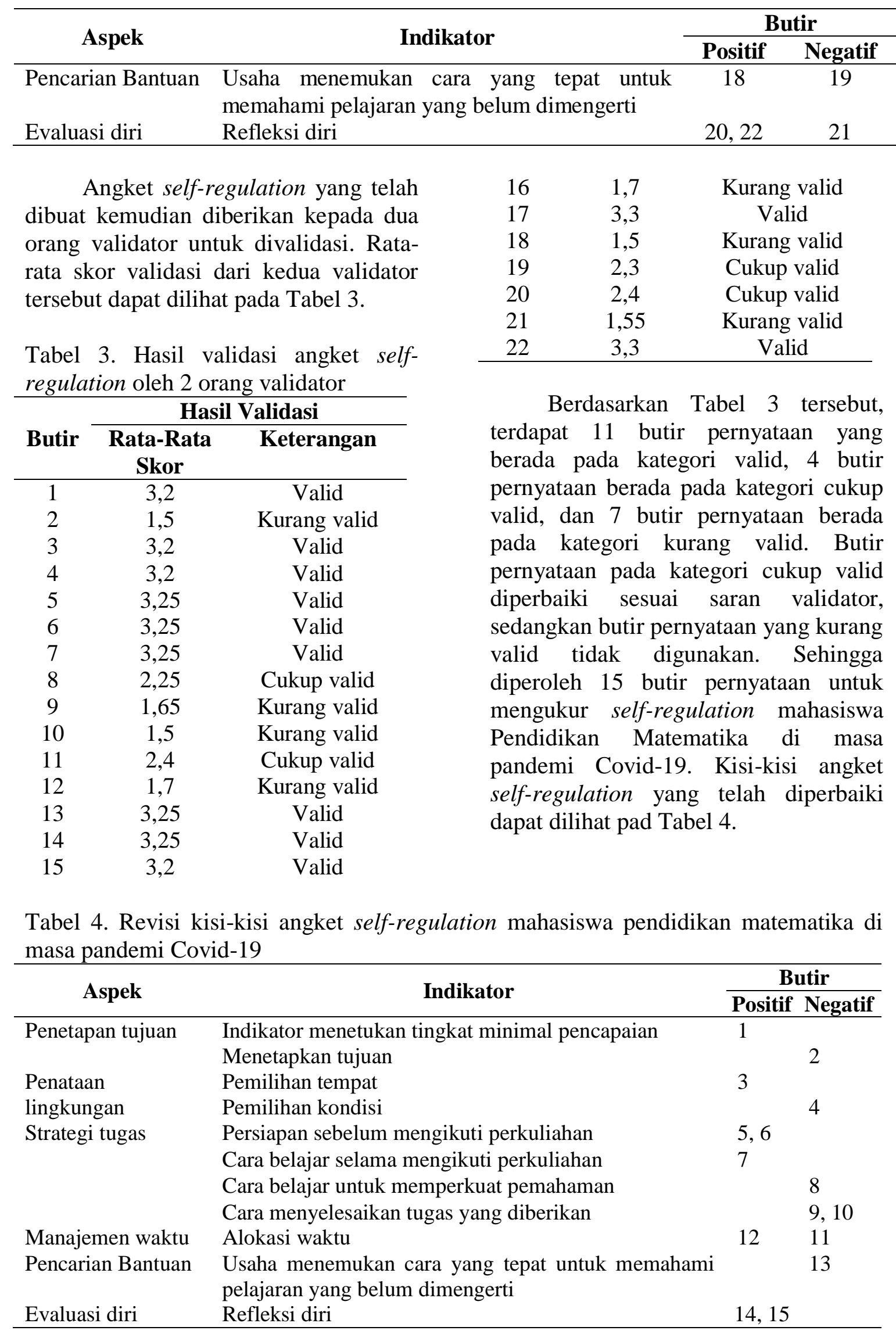


DOI: https://doi.org/10.24127/ajpm.v10i3.3870

Angket self-regulation yang telah diperbaiki berdasarkan saran validator kemudian diujicobakan kepada 59 orang mahasiswa Pendidikan Matematika Universitas Riau angkatan 2016. Skor yang diperoleh setiap mahasiswa pada masing-masing butir pernyataan kemudian dihitung. Selanjutnya skor tersebut diubah dari data ordinal ke data interval menggunakan metode MSI. Setelah itu perhitungan koefisien validitas dan reliabilitas angket selfregulation dapat dilakukan menggunakan bantuan SPSS dan Microsoft excel. Ringkasan penghitungan skor validitas dan reliabiltitas angket dapat dilihat pada Tabel 5.

Tabel 5. Ringkasan hasil pengujian validitas angket self-regulation

\begin{tabular}{cccc}
\hline Butir & t hitung & t tabel & Keterangan \\
\hline 1 & 4,49 & 2 & Valid \\
2 & 7,73 & 2 & Valid \\
3 & 4,65 & 2 & Valid \\
4 & 4,38 & 2 & Valid \\
5 & 3,93 & 2 & Valid \\
6 & 6,26 & 2 & Valid \\
7 & 4,9 & 2 & Valid \\
8 & 7,37 & 2 & Valid \\
9 & 7,03 & 2 & Valid \\
10 & 5,42 & 2 & Valid \\
11 & 6,88 & 2 & Valid \\
12 & 5,79 & 2 & Valid \\
13 & 5,16 & 2 & Valid \\
14 & 4,12 & 2 & Valid \\
15 & 4,14 & 2 & Valid \\
\hline
\end{tabular}

Tabel 5 tersebut memperlihatkan lima belas butir pernyataan yang mengukur self-regulation tersebut telah valid. Perhitungan kemudian dilanjutkan untuk melihat reliabilitas angket yang dibuat. Dengan bantuan SPSS, diperoleh koefisien $r=0,86$. Dari nilai $r$ ini kemudian dihitung nilai $t$ nya dan diperoleh $t_{\text {hitung }}=12,62$. Nilai $t_{\text {hitung }}$ ini dibandingkan dengan $t_{\text {tabel }}=2$, yaitu $t_{\text {hitung }}>\mathrm{t}_{\text {kritis. }}$. Berarti, angket selfregulation yang dibuat reliabel.
Angket untuk mengukur selfregulation mahasiswa pendidikan matematika di masa pandemi Covid-19 yang dibuat telah valid dan reliabel, sehingga sudah dapat digunakan. Uraian butir pernyataan angket self-regulation yaitu sebagai berikut.

Aspek penetapan tujuan terdiri dari dua indikator. Indikator pertama yaitu "Menentukan tingkat minimal pencapaian", dengan butir pernyataan "Saya mempunyai standar yang harus saya capai dalam mengikuti setiap matakuliah di Program Studi Pendidikan Matematika". Indikator kedua yaitu "Menetapkan tujuan", dengan butir pernyataan "Saya hanya sekedar memenuhi target absensi saat mengikuti perkuliahan daring tanpa memiliki tujuan yang jelas".

Aspek penataan lingkungan terdiri dari dua indikator. Indikator pertama yaitu "Pemilihan tempat", dengan butir pernyataannya "Saya selalu memilih tempat yang paling nyaman untuk mengikuti perkuliahan daring agar bisa berkonsentrasi". Indikator kedua yaitu "Pemilihan kondisi", dengan butir pernyataannya yaitu "Saya melakukan kegiatan lain ketika mengikuti perkuliahan daring".

Aspek strategi tugas terdiri dari empat indikator. Indikator pertama yaitu "Persiapan sebelum mengikuti perkuliahan". Indikator pertama memuat dua butir pernyataan yaitu "Saya mempelajari materi kuliah yang akan dipelajari sebelum kuliah daring dimulai" dan "Saya membuat catatan pertanyaan yang akan saya tanyakan kepada dosen saat kuliah daring berlangsung". Indikator kedua yaitu "Cara belajar selama mengikuti perkuliahan", dengan butir pernyataan "Saya membuat catatan materi perkuliahan di setiap pertemuan meskipun perkuliahan dilakukan secara 
daring". Indikator ketiga yaitu "Cara belajar untuk memperkuat pemahaman", dengan butir pernyataannya yaitu "Ketika saya merasa sudah memahami materi perkuliahan pada mata kuliah matematika, saya merasa tidak perlu berlatih soal-soal apabila tidak ditugaskan dosen". Indikator keempat yaitu "Cara menyelesaikan tugas yang diberikan". Indikator keempat memuat dua butir pernyataan yaitu "Setiap diberikan tugas dari perkuliahan daring, saya menunggu kiriman jawaban dari teman lainnya di grup media sosial" dan "Saya tidak akan melanjutkan mengerjakan tugas jika terbentur dan tidak menemukan solusi penyelesaian". Aspek manajemen waktu, indikatornya yaitu "Alokasi waktu" yang memuat dua butir pernyataan. Pernyataan pertama yaitu "Selama pandemi covid-19, saya hanya belajar saat kelas daring, saat mengerjakan tugas, dan saat akan ujian". Sedangkan pernyataan kedua yaitu "Selama masa pandemi covid-19 saya mengalokasikan waktu untuk belajar setiap hari”.

Aspek pencarian bantuan, indikatornya yaitu "Usaha menemukan cara yang tepat untuk memahami pelajaran yang belum dimengerti". Butir pernyataan yang mewakili aspek dan indikator ini yaitu "Saya malu bertanya kepada dosen ataupun teman, baik melalui grup maupun pesan pribadi, jika saya menemui kesulitan dalam belajar".

Aspek evaluasi diri, indikatornya yaitu "Refleksi diri". Butir pernyataan yang mewakili aspek evaluasi diri dan indikator refleksi diri yaitu "Saya berdiskusi dengan teman, baik di grup, pesan pribadi, ataupun tatap muka untuk mengecek pemahaman saya mengenai suatu materi kuliah daring" dan "Menurut saya penting untuk melakukan refleksi terhadap kekurangan saya di suatu mata kuliah, terlebih di mata kuliah yang nilai tugas atau nilai kuisnya rendah".

Dalam penelitian ini dihasilkan angket self-regulation mahasiswa pendidikan matematika yang valid dan reliabel di masa Pandemi Covid-19. Hal ini disebabkan sebelum angket diberikan kepada mahasiswa untuk mengukur self-regulation, angket tersebut divalidasi oleh validator dan diujicobakan kepada mahasiswa pendidikan matematika. Sebagaimana yang dinyatakan oleh Dewi dan Sudaryanto bahwa uji validitas dan reliabilitas suatu angket sangat penting untuk dilakukan, karena mempengaruhi data-data yang akan peneliti peroleh dari angket tersebut (Dewi \& Sudaryanto, 2020).

Kelebihan penelitian ini yaitu tahap-tahap pengembangan yang direncanakan telah dilakukan, angket yang diperoleh telah divalidasi oleh ahli dan diujicobakan kepada mahasiswa Pendidikan Matematika, serta telah memperoleh angket self-regulation mahasiswa Pendidikan Matematika di masa Pandemi Covid-19 yang belum ada sebelumnya. Kekurangan penelitian ini yaitu penelitian ini terbatas pada pengembangan angket yang hanya mengukur self-regulation, sedangkan masih terdapat aspek lain yang belum dikembangkan instrumennya.

Penelitian ini memiliki kesamaan dengan penelitian yang dilakukan oleh Muhtarom, Juniati, dan Siswono yang memperoleh angket keyakinan terhadap pemecahan masalah dan pembelajaran matematika yang valid dan reliabel (Muhtarom et al., 2017). Zuliani, Florentinus, dan Ridlo melalui penelitiannya memperoleh instrument penilaian karakter pada siswa kelas IV Sekolah Dasar yang valid dan reliabel (Zuliani et al., 2017). Selanjutnya Sa'adah yang mengembangkan angket minat siswa terhadap proses 
DOI: https://doi.org/10.24127/ajpm.v10i3.3870

pembelajaran matematika juga memperoleh angket yang valid (Sa'adah, 2020). Pada penelitianpenelitian tersebut, telah diperoleh instrumen yang valid dan reliabel, tetapi belum ada yang mengukur selfregulation mahasiswa pendidikan matematika. Oleh karena itu, instrumen angket self-regulation pada penelitian ini dapat digunakan untuk mengukur self-regulation mahasiswa pendidikan matematika.

Implikasi hasil penelitian ini secara teoritis dapat menambah teori ataupun literatur terkait bagaimana mengembangkan instrumen yang dapat mengukur self-regulation mahasiswa pendidikan matematika dalam pembelajaran daring dan aspek self-regulation apa yang diukur. Secara praktis, angket self-regulation yang dihasilkan dari penelitian ini dapat digunakan untuk mengukur self-regulation mahasiswa pendidikan matematika dalam pembelajaran daring.

Penelitian ini berfokus untuk mengembangkan angket self-regulation mahasiswa Pendidikan Matematika di masa pandemi Covid-19. Dalam proses pembelajaran, tidak hanya selfregulation yang perlu diukur. Selfconcept, self-confidence, dan lain sebagainya juga perlu untuk diukur. Selain itu, saat ini beberapa lembaga pendidikan telah mulai melaksanakan pembelajaran tatap muka terbatas. Situasi, kondisi, respon, tanggapan, dan cara mahasiswa beradaptasi pada pembelajaran ini tentu memiliki perbedaan dengan pembelajaran yang dilakukan secara daring sepenuhnya. Oleh karena itu, pengembangan angket selanjutnya dapat dilakukan dengan mengacu pada situasi saat pembelajaran tatap muka terbatas tersebut.

\section{KESIMPULAN DAN SARAN}

Berdasarkan hasil dan pembahasan, dapat disimpulkan bahwa angket yang dikembangkan telah memenuhi syarat valid dan reliabel, sehingga digunakan untuk mengukur self-regulation mahasiswa Pendidikan Matematika di masa pandemi Covid-19. Angket memuat 15 butir pernyataan yang diturunkan dari 11 indikator, yaitu indikator menetukan tingkat minimal pencapaian, menetapkan tujuan, pemilihan tempat, pemilihan kondisi, persiapan sebelum mengikuti perkuliahan, cara belajar selama mengikuti perkuliahan, cara belajar untuk memperkuat pemahaman, cara menyelesaikan tugas yang diberikan, alokasi waktu, usaha menemukan cara yang tepat untuk memahami pelajaran yang belum dimengerti, dan refleksi diri.

Saran untuk penelitian selanjutnya yaitu angket yang akan dikembangkan dapat mengacu pada situasi dan kondisi terbaru terkait penanganan Covid-19. Seperti pengembangan angket untuk mengukur self-regulation dalam proses pembelajaran tatap muka terbatas.

\section{DAFTAR PUSTAKA}

Bai, B., \& Guo, W. (2021). Motivation and Self-Regulated Strategy Use: Relationships to Primary School Students' English Writing in Hong Kong. Language Teaching Research, 25(3), 378-399. https://doi.org/10.1177/13621688 19859921

Barnard-brak, L., Lan, W. Y., \& Paton, V. O. (2010). Learning Environment Self-Regulated Learning. International Review of Research in Open and Distance Learning, 11(1), 61-80. https://doi.org/10.19173/irrodl.v1 $1 \mathrm{i} 1.769$ 
Bol, L., \& Garner, J. K. (2011). Challenges in supporting selfregulation in distance education environments. Journal of Computing in Higher Education, 23(2-3), 104-123. https://doi.org/10.1007/s12528011-9046-7

Chaves-Barboza, E., Trujillo-Torres, J. M., López-Núñez, J. A., \& SolaMartínez, T. (2017). Actions and Achievements of Self-Regulated Learning in Unique Environments. Research on Students Participating in the Graduate Program in Preschool Education at the University of Granada. Journal of New Approaches in Educational Research, 6(2), 135-143. https://doi.org/https://doi.org/10.7 821/naer.2017.7.236

Cheng, E. C. K. (2011). The Role of Self-Regulated Learning in Enhancing Learning Performance. The International Journal of Research and Review, 6(1), 1-16.

Dema, C., \& Sinwongsuwat, K. (2020). Enhancing EFL Students' Autonomous Learning of English Conversation During COVID-19 Via Language-in-talk Log Assignments. Education Quarterly Reviews, 3(4), 598615.

https://doi.org/10.31014/aior.1993 .03 .04 .165

Dewi, S. K., \& Sudaryanto, A. (2020). Validitas dan Reliabilitas Kuisioner Pengetahuan , Sikap dan Perilaku Pencegahan Demam Berdarah. Prosiding Seminar Nasional Keperawatan Universitas Muhammadiyah Surakarta, 73-79. Program Studi Keperawatan, Universitas Muhammadiyah Surakarta.
Goulão, M. de F., \& Menedez, R. C. (2015). Learner Autonomy and Self-regulation in eLearning. Procedia - Social and Behavioral Sciences, 174, 1900-1907. https://doi.org/10.1016/j.sbspro.20 15.01.853

Lin, J. W., Lai, Y. C., Lai, Y. C., \& Chang, L. C. (2016). Fostering self-regulated learning in a blended environment using group awareness and peer assistance as external scaffolds. Journal of Computer Assisted Learning, 32(1), 77-93. https://doi.org/10.1111/jcal.12120

Macejka, M. (2014). The Role of Grade Level and Locus of Control in Self- Regulated Learning Strategies of College Students. Journal of Education, Psychology and Social Sciences, 1(2), 13391488.

Meesong, P. K., \& Jaroongkhongdach, W. (2016). Autonomous Language Learning: Thai Undergraduate Students' Behaviors. Thai TESOL Journal, 29(2), 156-186.

Muhtarom, Juniati, D., \& Siswono, T. Y. E. (2017). Pengembangan Angket Keyakinan Terhadap Pemecahan Masalah dan pembelajaran Matematika. JIPMat, 2(1), 55-64. https://doi.org/10.26877/jipmat.v2 i1.1481

Qadaristin, D. F. L. (2021). Assessing Self-Regulated Learning in Primary School: A Systematic Literature Review. OPTIMA: Journal of Guidance and Counseling, 1(1), 55-72.

Rapanta, C., Botturi, L., Goodyear, P., Guàrdia, L., \& Koole, M. (2020). Online University Teaching During and After the Covid-19 
DOI: https://doi.org/10.24127/ajpm.v10i3.3870

Crisis: Refocusing Teacher Presence and Learning Activity. Postdigital Science and Education, 2(3), 923-945. https://doi.org/10.1007/s42438020-00155-y

Sa'adah, N. (2020). Analisis Validasi Pengembangan Angket Minat Siswa Terhadap Proses Pembelajaran Matematika. $E d$ Humanistics : Jurnal Ilmu Pendidikan, 5(1), 624-627. https://doi.org/10.33752/edhumanistics.v5i1.702

Siregar, H. M., \& Siregar, S. N. (2021). Profil Self Regulation Mahasiswa Pendidikan Matematika FKIP Universitas Riau di Masa Pandemi Covid-19. ANARGYA: Jurnal Ilmiah Pendidikan Matematika, 4(1), 1-10. https://doi.org/10.24176/anargya.v $4 \mathrm{i} 1.5601$

Subekti, F. E., \& Akhsani, L. (2020). Pengembangan Modul Statistika Deskriptif Berbasis Pemecahan Masalah. AKSIOMA: Jurnal Program Studi Pendidikan Matematika, 9(3), 530-539. https://doi.org/10.24127/ajpm.v9i 3.2869

Yen, C.-J., Tu, C.-H., Sujo-Montes, L., \& Sealander, K. (2016). A Predictor for PLE Management: Impacts of Self- Regulated Online Learning on Students' Learning Skills. Journal of Educational Technology Development and Exchange, 9(1), 29-48. https://doi.org/10.18785/jetde.090 1.03

Zimmerman, B. J. (2015). SelfRegulated Learning: Theories, Measures, and Outcomes. International Encyclopedia of the Social \& Behavioral Sciences: Second Edition, 541-546. https://doi.org/https://doi.org/10.1 016/B978-0-08-097086-8.26060-1 Zuliani, D., Florentinus, T. S., \& Ridlo, S. (2017). Pengembangan Instrumen Penilaian Karakter pada Siswa Kelas IV Sekolah Dasar. Journal of Educational Research and Evaluation, 6(1), 46-54. https://doi.org/10.15294/jrer.v6i1. 16207 